\title{
HYDATID CYST OF THE UTERINE CERVIX
}

\author{
Ishraq Dhaifalah
}

\author{
Department of Gynaecology and Obstetric, Althawra Hospital, Sana'a Yemen Rep. \\ Department of Human Genetic and Fetal Medicine, University Hospital, I. P. Pavlova 6, 775 20 Olomouc, Czech Republic
}

Received: October 10, 2001

Key words: Hydatid cyst / Uterine cervix / Localisation / Diagnosis / Treatment

I report and discuss a very rare case of primary involvement of the uterine cervix by hydatid cyst a parasitic disease caused by Echinococcus granulosus, whose first and most important site is the liver. The case was misdiagnosed as an ovarian cyst until the time of operation.

And this is to alert the gynaecologist to the possibility of hydatid cyst when a septated mass is found in the pelvis.

\section{INTRODUCTION}

Hydatid disease is an illness caused by the cystic phase of the small tapeworm's Echinococcus granulosus, whose primary host is the dog and whose cysts affect sheep, commonly causing unilocular cyst. The rare E. multilocularis tapeworms affect foxes, and cysts are found in small rodents too and those are the once causing the alveolar type ${ }^{1,3}$. Human disease occurs when tapeworm ova are ingested by humans, often as a result of close contact with a working or pet dog and often acquired in childhood ${ }^{1,8}$. The disease is most common in the sheep-raising areas of the world, including South Africa, Australia, New Zealand, the Middle East, Central Europe, and South America ${ }^{8}$. The majority of cysts are found in the liver or the lung. After remaining asymptomatic for decades, the enlarging cysts in the liver may produce abdominal pain or swelling, or may obstruct the biliary system, leading to jaundice. Lung cysts can cause partial bronchial obstruction, with repeated chest infection. Severe anaphylactoid reaction and urticaria occurs in case of rupture of the cysts ${ }^{1,8}$. The brain can be also affected mainly by metastases of E. multilocularis ${ }^{1}$. Echinococcal cysts may also involve the cervix ${ }^{6}$, which can be the primary or a secondary site of infection. Plain radiographs and ultrasound scans will reveal thin-walled, fluid filled structures. Computed tomographic scans may reveal daughter cysts, and on magnetic resonance scans magnified images may demonstrate scolices within them. ELISA tests, used to detect cyst-associated hydatid antibodies, are highly sensitive. Antigen detection testes can be useful in making diagnosis in acute cases, more importantly, in monitoring the response to chemotherapy ${ }^{1,7}$. Surgical excision offers the only hope of cure ${ }^{8}$; a common approach is to prepare patients for operation with albendazole for at least 2 weeks or to give this drug for non-operable cases, as cysts of the brain. Praziquantal is also given preoperatively and for 2 weeks following to act against the protoscolices and reduce the risk of secondary seeding ${ }^{1,8}$.
In cases of cervical cysts surgical excision is the treatment of choice ${ }^{6}$.

I report here a case of hydatid cyst of the uterine cervix, which is one of the extremely rare involved sites.

\section{CASE REPORT}

A 32-years-old women, gravida 6, para 3 and with 3 abortions, was referred to us with lower abdominal pain and lower back pain. Previous medical history was unremarkable; surgically the patient had had a caesarean section four years previously for transverse lie. The patient gave a history of non-specific abdominal and pelvic discomfort that was accompanied by some lower back pain. General examination showed no abnormality. On pelvic examination a mass of $7-8 \mathrm{~cm}$ in diameter was found in the right lower part of the uterus. It was not possible to differentiate this from the right parametrium. The left parametrium was free.

On Ultrasonography, a large septated and cystic mass of about $8 \times 8 \mathrm{~cm}$ was found to the right side of the uterus with a very close relationship between the uterus and the parametrium. Ultrasonographic examination demonstrated no other disease in the abdomen. Histological examination of the cervix revealed no pathology. The remainder of the physical, gynaecological and laboratory analysis, such as blood pressure, pulse, fasting plasma glucose, electrolytes, renal and liver function tests and chest X-ray were all normal.

The diagnosis of ovarian cyst was determined and the patient was prepared for operation. Laparotomy through a paramedian longitudinal incision (the site of previous caesarean section) revealed that the right ovary was normal in size and adhered to a subserous cystic mass on the supravaginal portion of the cervix. The uterine fundus, body and left parametrium were normal. During the trial of cyst excision it ruptured, and the scolices the brood capsules were seen. Only then was the diagnosis of hydatid cyst made, and because of the rup- 
ture and the difficulty of excision of the cyst, and the adherence of the right ovary, abdominal hysterectomy with right salpigo-oophorectomy was performed.

During macroscopic analysis the uterus weighed $140 \mathrm{~g}$. On the right side of the lower part of the uterus, under the serosa and inside the myometrium a yellow coloured irregular cystic cavity measuring $7 \times 5 \times 4 \mathrm{~cm}$, with a lot of chitinous layers of cysts was found with no other pathology.

The diagnosis of hydatid cyst was conformed histologicaly and the indirect heamagglutination test was positive in 1/260 titration. After definite diagnosis postoperatively we started albendazole therapy in doses of $10 \mathrm{mg} / \mathrm{kg} /$ day for 10 weeks as a prophylactic. The patient progressed well and was discharged on the $8^{\text {th }}$ day post operatively. After 2 months follow-up patient was asymptomatic.

\section{COMMENT}

Hydatid cyst is a parasitic disease caused by Taenia Echinococcus. Primary uterine hydatid cyst is an extremely rare condition. I found only a few reports in the literature ${ }^{2,3,5}$. Based on this reported case, a hydatid cyst of the uterus underlines the difficulties of diagnosis outside the endemic zones and in this very rare localisation. The misdiagnosis in my opinion is one of the reasons leading to the complication of hysterectomy in young women, but the patient was lucky enough that she already has 3 children. There was no chance for the patient to undergo full investigations to reach the correct diagnosis.
Computed tomographic scans that can reveal daughter cysts and magnetic resonance scans magnified images that may demonstrate scolices within them, was not done for this patient. This type of investigation will give a better result whatever the diagnosis. From this experience, I suggest that the gynaecologists should be aware of the possibility of a hydatid cyst when they find septated cystic mass in the pelvis. And also if hydatid cyst is diagnosed after operation, in addition to the complication of rupture, the treatment with medication such as albendazole should be started as a prophylaxis.

\section{REFERENCES}

1. Bannister, B., Begg, N., Gillespie, S. (2000) Infectious disease: second edition, P 506. Blackwell Science, United Kingdom.

2. Gueddana, F., Chemmen, L., Lebbi, I., Koubaa, A., et al. (1990) Intrauterine hydatidosis. A case report. J. Gynecol. Obstet. Biol. Reprod (Paris) 19, 725-7277.

3. Komongui, D. G., Diouf, A., Dao, B., Gentile, B., Bah, M. D., Diadhiou, P. (1990) Uterine hydatid cyst (a clinical review related to a case which was diagnosed at the Dakar University Hospital Gynaecology and Obstetrics clinic) Dakar Med. 35, 162-167.

4. Mendell, G. L., Douglas, R. G., Bernet, J. E. (1990) Principles and Practice of infectious Diseases. P 2155. Churchill Livingstone, New York.

5. Okmus, Y., Tayyar, M., Patiroglu, T., Aygen, E. (1994) Uterine hydatid cyst. International Journal of Gynaecology and Obstetrics 45, 51-53.

6. Pernoll, Martin L., \& Benson, Ralph C. (1987) Current Obstetric \& Gynecologic Diagnosis and treatment, p 1139. Middle East edition, sixth, Lebanon.

7. RoFo. (1997) Echinokokkuszyste und Uterus myomatosus. Fortschritte auf dem Gebiete der Rontgenstrahlen und der neuen bildgebenden Verfahren (Germany) 166, 590-593.

8. The Merck Manual. 